\section{MAFIA TRIVIA}

Sir, I would like to correct D. Burton (It is reprehensible. BDJ 2010; 209: 592) on his Mafia trivia. The 'signature or brains' contract was the brainchild, if you'll excuse the expression, of Vito Corleone, not Al Capone.

C. Charalambou

DOI: 10.1038/sj.bdj.2011.100

\section{RISK-BENEFIT ASSESSMENTS}

Sir, abnormal positions of impacted teeth are commonly observed during routine radiographic examination. ${ }^{1}$ of these, a total inversion of the involved tooth with the crown pointing towards the maxillary sinus and root apex towards the alveolar crest is considered to be quite rare. ${ }^{2}$ Of the six reported cases of inverted teeth, two were of impacted maxillary third molars. Asymptomatic inverted maxillary third molars are usually managed conservatively as surgical removal is often rendered difficult due to poor accessibility and the risk of inadvertent slippage of the tooth into the maxillary sinus or infratemporal fossa. ${ }^{3}$

A 30-year-old female reported to the dental clinic with a chief complaint of pain in the left maxillary posterior region for the past week. No significant dental and medical history was elicited. Clinical examination revealed a missing 28 with a distal periodontal pocket in relation to 27. An intraoral and panoramic radiograph revealed the presence of an impacted maxillary third molar in an inverted position (Fig. 1). Improving the distal periodontal pocket was considered to be difficult due to the presence of the impacted 28 and the patient was given the option to consider surgical removal of the impacted molar. Informed consent was obtained and the tooth was extracted by the transalveolar method. Care was taken to prevent accidental displacement of teeth into the infratemporal fossa or creation of oroantral com-

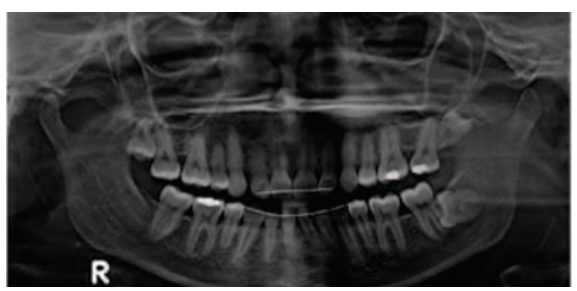

Fig. 1 Panoramic view showing inverted molar on left side munication. The postoperative period was uneventful. A careful risk-benefit assessment is mandatory prior to surgical removal of such inverted maxillary third molars.

V. Yuvaraj, B. Krishnan, V. Murthy, S. Prasad Bhopal

1. Dachi S F, Howell FV. Exodontia. A survey of 3,874 routine full mouth radiographs: a study of impacted teeth. Oral Surg Oral Med Oral Pathol 1961; 14: 1165-1169.

2. Gold J, Demby N. Rare inverted maxillary third molar impaction: report of case. J Am Dent Assoc 1973; 87: 186-188.

3. Oberman M, Horowitz I, Ramon Y. Accidental displacement of impacted maxillary third molars. Int J Oral Maxillofac Surg 1986; 15: 756-758.

DOI: 10.1038/sj.bdj.2011.101

\section{PINE MOUTH}

Sir, we would like to draw readers' attention to a case of a patient complaining of a bad taste (cacogeusia) - specifically metallogeusia.

A 47-year-old male presented reporting a metallic taste (metallogeusia) and a soapy/woolly sensation to the tongue and lips which persisted for six weeks. His medical history was non-contributory: he had no recent trauma to the head or neck, no paranasal sinus problems, and his social history was also unremarkable - he was a non-smoker, moderate alcohol drinker, and he was neither stressed nor depressed. He denied any change in diet, new medication (over the counter or prescribed) or any herbal supplements. However, he suspected the symptom was attributed to eating Chinese pine nuts. Upon clinical examination no oral abnormality was detected and cranial nerves were grossly intact. The symptoms resolved with no treatment other than avoiding further pine nuts, and he has had no sequelae.

'Pine mouth' appears to be an emerging problem but is relatively benign. Pine nuts are edible seeds and most of those on the market belonging to the Pinus genus. The nuts are consumed in sauces (pesto), salads and desserts. Over the past few years, cases of taste disturbances following the consumption of pine nuts have been reported by food agencies and on public Internet websites, and there is a single full paper in the scientific literature. ${ }^{1}$ Pine mouth was, however, first noted in 2001 in an abstract from a European medical conference. ${ }^{2}$
It has been hypothesised that a polyunsaturated fatty acid ( $\Delta 5$-olefinic acid) in pine nuts becomes oxidised causing the rancid taste. Raw, cooked and processed pine nut have all been implicated. ${ }^{3-5}$ We would be interested to hear of any patients with similar symptoms.

R. Hampton, C. Scully, S. Ellison

Bristol

1. Munk M D. 'Pine Mouth' syndrome: Ccacogeusia following ingestion of pine nuts (genus: pinus). An emerging problem? J Med Toxicol 2010; 6: 158-159.

2. Mostin M. Taste disturbances after pine nut ingestion. Presented at the XXXVIII Congress of the Society for Clinical Toxicology (abstract). J Emerg Med 2001; 8: 76.

3. Destaillats F, Cruz-Hernandez C, Giuffrida F, Dionisi F. Identification of the botanical origin of pine nuts found in food products by gas-liquid chromatography analysis of fatty acid profile. J Agric Food Chem 2010; 58: 2082-2087.

4. Sharashkin L, Gold M. Pine nuts (pignolia): species, products, markets and potential for US production. In Northern Nut Growers Association 95th Annual Report, Proceeding for the 95th annual meeting, Columbia, Missouri. 16-19 August 2004.

5. Pine nuts associated with a bitter aftertaste. 16 July 2009. Accessed at: http://www.food.gov.uk/ news/newsarchive/2009/jul/pinenut

DOI: 10.1038/sj.bdj.2011.102

\section{VOODOO DENTISTRY}

Sir, on a recent edition of Desert Island Discs the guest who was marooned on the island was Tony Iveson. He was a pilot in the Second World War and flew both bombers and fighter planes. He told us that the military were very keen that their pilots should have good dental health so that it did not compromise their ability to fly.

The dentist who examined him had recently come back from New York and had a Frank Sinatra song playing in the background which Tony chose as his first piece of music to take on the island. Background music must have been very unusual in the 1940s, but what was even more interesting were the lyrics of the song that was being played:

You do something to me

Something that simply mystifies me

Tell me why should it be

You have the power to hypnotise me

Let me live "neath your spell

Do, do that voodoo that you do so well You do something to me

That nobody else can do

...which could hardly have been more appropriate for a dental patient!

B. T. H. Devonald

Coleby

DOI: 10.1038/sj.bdj.2011.103 